\title{
CÂNCER E TRABALHO: DOS PROCESSOS DE SUBJETIVAÇÃO AO CONTROLE NO CURSO DE VIDA
}

\author{
CANCER AND WORK: FROM SUBJECTIVATION PROCESSES TO CONTROL IN THE \\ LIFE COURSE
}

Luciano Luiz Alt ${ }^{1}$

Cleide Fátima Moretto

\begin{abstract}
RESUMO
O diagnóstico de câncer traz mudanças na vida das pessoas, interferindo, inclusive, nos sentimentos dirigidos ao trabalho. No contexto contemporâneo de aumento da prevalência do câncer e de sobrevida ligada à doença, o trabalho pode apresentar sentidos e significados próprios, oferecendo um novo campo de estudo. O artigo buscou compreender o papel do trabalho no curso de vida e no processo de adoecimento por câncer em trabalhadores ativos. Para isso se realizou um estudo qualitativo, de natureza exploratória e descritiva, utilizando duas formas de abordagem dos sujeitos, todos trabalhadores ativos com diagnóstico de câncer: entrevistas individuais semiestruturadas e um grupo focal, por meio da aplicação de um roteiro com questões norteadoras. O conteúdo das falas foi analisado com base nas categorias preestabelecidas "processos de subjetivação do trabalho para a pessoa com câncer" e "controle e normalidade da vida por meio do trabalho". Os participantes sinalizaram a ressignificação da vida e do trabalho e confirmam o papel do trabalho enquanto meio de controle e normalidade da vida diante do diagnóstico e do tratamento do câncer.
\end{abstract}

Palavras-chave: câncer, significado do trabalho, identidade, normalidade, controle.

\begin{abstract}
The diagnosis of cancer brings many changes to people's lives, sometimes even interfering with work-related issues. In the contemporary context, considering the increase in the prevalence of cancer and survival linked to the disease, work can have its own meanings from the perspective of a cancer patient, which is a field of study that should be explored. Therefore, this study investigated the importance of work in the course of life and the illness management process of employed cancer patients. A qualitative, exploratory, and descriptive study was carried out. Data collection included semi-structured individual interviews and a focus group with a questionnaire guide. The information was analyzed based on the pre-established categories: 1) strategies of subjectivation of work for the person with cancer and 2) control and normality of life through work. Participants talked about the resignification of life and confirmed the importance of work as a way of being in control and getting back to their normal life in the face of cancer diagnosis and treatment.
\end{abstract}

Keywords: cancer, meaning of work, identity, normality, control.

\footnotetext{
Doutorando em Envelhecimento Humano pelo Programa de Pós-Graduação em Envelhecimento Humano (PPGEH), Universidade de Passo Fundo (UPF). Mestre em Envelhecimento Humano (PPGEH) pela Universidade de Passo Fundo (UPF). Docente da Faculdade de Medicina da UPF. E-mail: alt.luciano.upf.@gmail.com

2 Doutora em Teoria Econômica pela Universidade de São Paulo (USP). Mestre em Economia pela Universidade Federal do Rio Grande do Sul (Ufrgs). Docente do Programa de Pós-Graduação em Envelhecimento Humano (PPGEH), Universidade de Passo Fundo (UPF).E-mail: moretto@upf.br
} 


\section{INTRODUÇÃO}

O trabalho, atividade essencialmente humana, traz consigo muito da complexidade do próprio indivíduo, sendo, frequentemente, central ou determinante para as mudanças nos ciclos de vida do sujeito, sobretudo para aquele que adoece (PETEET, 2000; DEBERT, 2010).

Dejours $(2005,2008)$ explica que o trabalho ocupa lugar de destaque na vida do homem, mas os sentidos e significados a ele atribuídos determinam o modo de encará-lo, se com prazer ou sofrimento. Portanto, se o trabalho permite autonomia e prazer, é esperado que o trabalhador tenha dificuldade no seu desengajamento, por outro lado, se gera adoecimento ou estafa, o trabalhador buscará ruptura com o mesmo. Assim, o trabalho pode ser desencadeador de alienação e de doenças, no entanto, mas pode também ser propulsor de gratificações e de saúde. Dejours (2011) adiciona que o trabalho atua como um estruturante psíquico, capaz de interferir na vida do indivíduo, podendo, inclusive, transformá-lo.

O trabalho não consiste apenas em uma forma de se ocupar, obter subsistência ou trazer ganhos pecuniários. Para muitos indivíduos, trabalhar significa estar inteiro, sentir-se apto em sua totalidade, sendo fundamental para manter a autoestima, bem como é um forte meio de construir de sua identidade, tanto subjetiva quanto social (CODO, 1997; ENRIQUEZ, 1999; MORIN, 2001; GILL, 2006; MORIN; TONELLI; PLIOPAS, 2007; FREUD, 2010; DEJOURS, 2011).

Já de acordo com Clot (2007), o trabalho preenche uma função psicológica exclusiva, que não pode ser completada por outra atividade, mantendo sua importância indiscutível. Além disso, o trabalho é essencial para o estabelecimento do autorreferenciamento do sujeito e de sua saúde, pois é o espaço no qual se pode obter a experiência dolorosa e decisiva do real, confrontando o indivíduo com as mais diversas situações, capazes de reafirmarem seu caráter e suas suscetibilidades físicas, psíquicas e sociais.

Marques (2007) complementa que o trabalho é percebido como criador de valor, sendo inerente ao cotidiano de cada pessoa, atuando no desenvolvimento do indivíduo, tanto pessoal quanto socialmente, além de proporcionar condições para a manutenção de sua dignidade. Ao associar tais significados às pessoas com câncer, pressupõem-se peculiaridades inerentes ao seu estado físico, emocional e social, incluindo questões gerais, mas ampliando percepções e valores aos processos de subjetivação do trabalho em relação àqueles que não se encontram doentes.

No âmbito dos estudos da psico-oncologia, como referem Peteet (2000) e Grunfeld e Cooper (2015), desengajar-se do trabalho, contra o desejo do indivíduo, pode causar-lhe ansiedade, como ocorre no adoecimento por câncer. De acordo com Kornblith (1998) e Peteet (2000), o papel que o trabalho ocupa no curso de vida das pessoas com câncer pode levar a compreender o processo de saúde-adoecimento, bem como as mudanças observadas quando do diagnóstico de uma neoplasia maligna.

O diagnóstico de câncer é um momento em que o indivíduo passa por transformações, inclusive em sua percepção do trabalho, o que pode levar até mesmo à ressignificação da própria existência e, por consequência, a forma de ver sua atividade laboral. Quando do diagnóstico de câncer, há uma ruptura da sequência natural esperada para a vida, que inclui a educação, a preparação para o mercado de trabalho, o exercício da atividade laboral, para, apenas depois, o desengajamento, pela aposentadoria. Esse curso pré-programado fica interrompido pelo câncer, fazendo com que muitos indivíduos apresentem dificuldades em se autorreferenciar, em encontrar seu lugar na família e na sociedade, bem como podem distanciar de si a ideia de normalidade, pois a doença a abala, em vários espaços da vida, inclusive em suas relações com o trabalho (PETEET, 2000; GILL, 2006). 
Evidencia-se, diante do contexto estabelecido, que atualmente o câncer é uma doença com alta incidência e prevalência em nível mundial. Apenas para o ano de 2017, nos Estados Unidos, estimam-se 1.688.780 novos casos (SIEGEL; MILLER; JEMAL, 2017). No Brasil, para o período 2016-2017, o Instituto Nacional do Câncer (INCA, 2016) estimou 600.000 novos casos, requerendo atenção especial, sobretudo em virtude de a doença atingir indivíduos em todas as idades, muitos em idade produtiva. Como destaca a Organização Mundial da Saúde (WORLD HEALTH ORGANIZATION, 2015), o câncer traz repercussões em diversas áreas da vida do indivíduo, envolvendo condições somáticas, psíquicas, familiares e sociais.

Ressalte-se, ainda, que o número de sobreviventes após o tratamento de neoplasias malignas vem aumentando exponencialmente, graças às melhorias observadas tanto nos mecanismos diagnósticos quanto nos terapêuticos (HEWITT; GREENFIELD; STOVALL, 2006; RAQUE-BOGDAN et al., 2015). Por esse motivo, são possíveis situações pouco usuais em outros períodos, exemplificadas pelo retorno de pessoas ao mercado de trabalho após terem sido acometidas por doenças graves como o câncer. No atual momento, em que muitas doenças, entre elas o câncer, conforme argumentam Duncan et al. (2012), atingiram o status de doença crônica, deve-se enfatizar que há muitas pessoas acometidas pela doença que se mantêm em condições de trabalho. De acordo com Carvalho (2008) e Longo et al. (2007), todo o espectro que essa situação envolve, desde a estigmatização social pela qual a pessoa com câncer ainda é submetida até o enfrentamento desta, remete a novas explorações sobre a reinserção dos indivíduos no mercado de trabalho durante ou após o câncer, bem como a capacidade de enfrentamento da doença no e pelo trabalho.

Tanto indivíduos que, ao ficarem doentes, buscam imediato afastamento de suas funções laborais quanto aqueles que, mesmo diante das dificuldades, encontram no trabalho um meio de enfrentamento para seguirem adiante, apresentam mudanças em sua percepção da atividade laboral. As questões referentes aos procedimentos terapêuticos a serem realizados ou a perda da aptidão física e emocional para seguir trabalhando, além da motivação para seguirem ativos e não se sentirem doentes, são expressos nessa relação. O trabalho, desta forma, constitui uma dualidade paradoxal para os trabalhadores que estão doentes de câncer (TAMMINGA et al., 2012; BARNARD; CLUR; JOUBERT, 2016).

Além disso, uma doença como o câncer que, durante muito tempo, era tida como "sentença de morte", vem adquirindo novo status na sociedade, muito além dos antigos estigmas. Dessa forma, o artigo objetiva compreender como o trabalho é percebido na perspectiva de pessoas com câncer em termos biopsicossociais, enfatizando os sentidos e significados do trabalho, a identificação delas com seu trabalho, bem como suas percepções de controle e normalidade da vida por meio do trabalho frente ao desajuste causado pelo adoecimento. Enfatize-se o advento de um novo cenário, no qual muitas pessoas com câncer têm se mantido ativas no trabalho durante e após a doença, tornando necessária atenção específica. Considerando-se que essa abordagem é ainda incipiente em todo o mundo, sobretudo no Brasil, e com base no que consta na literatura, justifica-se a importância de se evidenciar aspectos peculiares das pessoas com câncer nesse novo panorama desenhado pelos ganhos de sobrevida frente a essa doença, que hoje é entendida como crônica.

\section{MÉTODO}

Para conhecer as percepções dos indivíduos em relação à atividade laboral desempenhada e a representação da mesma em seu curso de vida diante do diagnóstico de câncer, realizou-se estudo descritivo e exploratório em nível qualitativo. O estudo foi desenvolvido com pessoas 
doentes de câncer, que realizam seu tratamento oncológico no Serviço de Oncologia do Hospital de Caridade de Carazinho, hospital de porte médio localizado em Carazinho, região norte do estado do Rio Grande do Sul, Brasil, referência em oncologia para atendimento de uma população de aproximadamente 200 mil habitantes.

A população incluída no estudo é representada por pessoas com mais de dezoito anos de idade que vinham exercendo atividade laboral ao serem acometidas pelo câncer e que realizavam tratamento oncológico em suas diversas modalidades (cirúrgica, quimioterápica, radioterápica, imunoterápica, hormonioterápica, transplante de medula óssea ou diferentes esquemas terapêuticos associados).

A opção pela abordagem qualitativa desta pesquisa contempla a observação de fenômenos que visam aos significados e interpretações, construindo categorias de análise, que permitem trazer a conhecimento variáveis epistemológicas (MINAYO, 2013). Pela abordagem qualitativa, como concebem Denzin e Lincoln (2011) e Flick (2009), os dados são analisados em seus contextos e, por meio deles, busca-se o entendimento ou a interpretação dos fenômenos em termos dos sentidos que as pessoas lhes atribuem.

A amostra deste estudo está composta por indivíduos que realizavam seu tratamento oncológico e que estavam trabalhando no momento do diagnóstico de câncer. $\mathrm{O}$ estudo atende aos critérios da Resolução 466/12 do Ministério da Saúde, tendo sido aprovado pelo Comitê de Ética e Pesquisa com Seres Humanos da Universidade de Passo Fundo por meio do parecer de número 1.776.319. Os participantes foram informados sobre a pesquisa e, após terem concordado em participar, assinaram o termo de consentimento livre e esclarecido.

No período de outubro de 2016 a maio de 2017, foram realizadas, inicialmente, 17 entrevistas individuais com a adoção de um roteiro de questões abertas (semiestruturado), mediante autorização para a gravação das falas. As questões foram dispostas de modo a oportunizar um espaço de escuta para as percepções e particularidades expressas pelas pessoas com câncer frente ao trabalho. As entrevistas individuais contemplaram indivíduos de ambos os gêneros, com idades que variaram entre 28 e 61 anos, economicamente ativos, utilizando-se o codinome E (numerado de E1 a E17, referindo-se às entrevistas individuais). O tamanho da amostra respeitou o critério de saturação de dados (SANDELOWSKY, 1995; FONTANELLA; RICAS; TURATO, 2008; FALQUETO; FARIAS, 2016). De modo complementar, foram obtidas falas provenientes da realização de um grupo focal, que contemplou seis indivíduos (diferentes daqueles entrevistados de maneira individual) de ambos os gêneros, com idades entre 24 e 51 anos, economicamente ativos, no intuito de ampliar a possibilidade de captação de diferentes percepções com base em um espaço coletivo e de identificação com a doença. Esses sujeitos foram identificados de E18 a E23.

Para a interpretação dos dados, após a degravação das falas, utilizou-se o método de análise de conteúdo. Ele foi escolhido por ser apropriado com relação aos objetivos do estudo, pois consta de um conjunto de técnicas de análise das comunicações baseado em procedimentos sistemáticos e objetivos de descrição do conteúdo das mensagens. Dentre as várias modalidades de análise do conteúdo, a análise temática de Bardin (2000) foi a escolhida, na perspectiva de colocar em evidência os núcleos de sentido que compõem a comunicação e cuja presença ou frequência de aparição podem significar algo para o objetivo analítico escolhido para este estudo de natureza qualitativa.

Para o escopo deste estudo, pela natureza de entrevistas individuais e grupos focais, buscou-se o enquadramento das falas em categorias previamente determinadas: processos de subjetivação do trabalho para a pessoa com câncer e controle e normalidade da vida por 
meio do trabalho. A primeira categoria contempla o modelo teórico dos sentidos e significados do trabalho e as relações entre estes e as mudanças no curso de vida das pessoas com câncer, esperando-se que o adoecimento interfira na forma como o trabalho é considerado. A segunda categoria enfoca as percepções dos indivíduos com câncer ante a doença e a importância do trabalho para a sensação de controle e normalidade sobre os atos da vida, crendo que ele seja um meio estruturado fundamental nesse processo. A linha de pesquisa eleita para a abordagem é a psico-oncologia.

O perfil dos entrevistados, com relação ao tipo de abordagem - entrevista individual ou participante de grupo focal na pesquisa -, à designação dos sujeitos participantes (de E1 a E23), à idade e ao gênero, à escolarização, à profissão, à situação em relação à População Economicamente Ativa (PEA), ao tempo de tratamento em anos e à situação na provisão da renda familiar estão demonstradas na Tabela 1.

\section{TABELA 1 - CARACTERÍSTICAS SOCIODEMOGRÁFICAS DOS PARTICIPANTES DA PESQUISA, POR MODALIDADE DE PARTICIPAÇÃO}

\begin{tabular}{|c|c|c|c|c|c|}
\hline Sujeito & $\begin{array}{c}\text { Idade } \\
\text { (anos) } \\
\text { Gênero }\end{array}$ & Escolarização & Profissão & $\begin{array}{c}\text { Tempo de } \\
\text { tratamento } \\
\text { (anos) }\end{array}$ & $\begin{array}{c}\text { Situação na } \\
\text { provisão da } \\
\text { renda } \\
\text { familiar } \\
\end{array}$ \\
\hline \multicolumn{6}{|c|}{ Individual } \\
\hline E1 & $40 \mathrm{~F}$ & Fundamental inc. & Zelador & 04 & Complementar \\
\hline E2 & $28 \mathrm{M}$ & Médio inc. & Operador de caixa & 01 & Principal \\
\hline E3 & $48 \mathrm{M}$ & Fundamental inc. & Serviços gerais & 02 & Principal \\
\hline E4 & $34 \mathrm{M}$ & Superior & Administrador & 04 & Compartilhada \\
\hline E5 & $55 \mathrm{M}$ & Fundamental inc. & Produtor rural & 02 & Principal \\
\hline E6 & $61 \mathrm{~F}$ & Fundamental inc. & Confeiteira & 02 & Complementar \\
\hline E7 & $50 \mathrm{~F}$ & Fundamental inc. & Do lar & 03 & Dependente \\
\hline E8 & $51 \mathrm{~F}$ & Superior & Professor & 01 & Compartilhada \\
\hline E9 & $34 \mathrm{~F}$ & Pós-graduação & Dentista & 01 & Compartilhada \\
\hline E10 & $58 \mathrm{~F}$ & Médio & Gerente & 01 & Compartilhada \\
\hline E11 & $55 \mathrm{~F}$ & Médio & Secretária & 08 & Complementar \\
\hline E12 & $45 \mathrm{~F}$ & Pós-graduação & Professor & 01 & Compartilhada \\
\hline E13 & $50 \mathrm{~F}$ & Superior & Professor & 07 & Compartilhada \\
\hline E14 & $56 \mathrm{M}$ & Médio & Gerente & 04 & Principal \\
\hline E15 & $49 \mathrm{M}$ & Fundamental inc. & Mecânico & 04 & Compartilhada \\
\hline E16 & $52 \mathrm{~F}$ & Médio & Técnico contab. & 01 & Complementar \\
\hline E17 & $33 \mathrm{~F}$ & Médio & Balconista & 04 & Principal \\
\hline \multicolumn{6}{|c|}{ Grupo Focal } \\
\hline E18 & $51 \mathrm{~F}$ & Médio & Comerciante & 01 & Complementar \\
\hline E19 & $29 \mathrm{M}$ & Médio inc. & Vendedor & 01 & Principal \\
\hline E20 & $28 \mathrm{~F}$ & Médio & Balconista & 01 & Principal \\
\hline E21 & $28 \mathrm{~F}$ & Médio & Aux. produção & 01 & Compartilhada \\
\hline E22 & $24 \mathrm{~F}$ & Médio & Vendedor & 01 & Complementar \\
\hline E23 & $35 \mathrm{M}$ & Médio & Técnico contab. & 01 & Complementar \\
\hline
\end{tabular}

Fonte: Primária, 2016/2017. 
A amostra integra a participação de 23 pessoas com câncer que estavam trabalhando no momento do diagnóstico da doença, portanto, todas economicamente ativas, com uma proporção maior de mulheres (15) em relação aos homens (8), com escolarização predominante nos níveis fundamental e médio (18), sendo os que têm ensino superior representados por menor número (5). A maioria deles se enquadra como chefes de domicílio ou provedores parciais de renda (22), ativos em diversas profissões. Onze deles estão em tratamento pelo período inferior a um ano, sendo que os demais estão em tratamento em período superior a um ano até oito anos.

\section{RESULTADOS E DISCUSSÃO}

Nas falas dos participantes foi possível identificar a percepção de sentidos e significados do trabalho com atributos como autorrealização, ter uma ocupação, sentimento de utilidade, meio de sobrevivência, forma de organizar a rotina, sair de casa, autoestima, dignidade, valorização, desafio, autonomia, liberdade, objetivo de vida, independência.

Muitos indivíduos veem o trabalho como edificante da própria identidade, sendo que demonstraram angústia pelo fato de não conseguirem trabalhar face à doença e às limitações que dela advêm, conforme enunciam Peteet (2000) e Grunfeld e Cooper (2015). Observa-se que, como decorrência do câncer, há o sentimento de perda, em que pese à capacidade de ser o provedor da família, de ser o profissional que desempenhava determinada atividade e, inclusive, do próprio convívio social, situações essas que conflituam e podem despersonalizar o indivíduo, causando-lhe desajustamento em seu autorreferenciamento.

Trabalhar, para muitos, significou a normalidade. Não trabalhar pode ser considerado anormal para eles. Quando se adoece de câncer, surgem sensações negativas, como instabilidade emocional, frustrações, ideia de dependência em qualquer de suas formas (física, emocional, financeira), depressão, medo e preocupações. O adoecimento coincide com a ideia de não poder trabalhar. Assim sendo, não trabalhar traz em si a ideia de perda de controle da vida, já que houve perda de controle sobre o próprio corpo, sobre a própria saúde.

Mesmo em tratamento oncológico, algumas pessoas seguem trabalhando. Porém, mesmo aquelas que não estão trabalhando podem buscar motivações para finalizar seus tratamentos, entre outros fatores, no retorno ao trabalho. Assim, para Peteet (2000) há a busca pela normalidade que se perdeu pelo câncer, e essa normalidade pode ser simbolizada pela manutenção do trabalho ou o retorno a ele.

\subsection{Processos de subjetivação do trabalho para a pessoa com câncer}

Para o ser humano, o trabalho significa muito mais que uma atividade remunerada capaz de promover o seu sustento e o de seus familiares. Significa, além disso, a forma como o indivíduo se enxerga na engrenagem social, com seu conceito de utilidade e lugar no mundo (DEJOURS, 1992; HARVEY, 2000; TOLFO; PICCININNI, 2007; BORGES; TAMAYO, 2011). Morin $(1996,2001)$ defende que, mesmo que os indivíduos não precisassem trabalhar para sua subsistência, poderiam buscar a integração, a vida com objetivos e as mais diversas relações com outras pessoas por meio do trabalho. Antunes $(1999,2008)$ argumenta que o homem busca, além da sobrevivência, a conquista de sua individualidade, a inserção social, a realização e a dignidade por meio do potencial emancipador do trabalho, que se mostra essencial à vida humana. Portanto, podem-se atribuir muitos sentidos e significados para o trabalho humano, além da simples necessidade de não perecimento. 
De outra parte, Lancman (2008) traz a ideia de que o trabalho deve ser entendido como uma atividade contínua, que se estende para além de seu espaço de execução, dessa forma influenciando em outras esferas da vida, inclusive no tempo de não trabalho. Esse conceito também é defendido por Codo, Sampaio e Hitomi (1998), os quais identificam que a vida do homem não pode se dar unicamente pelo trabalho, mas o sentido da vida não é efetivo na ausência dele. Dejours (2004) propõe que o trabalho é capaz de promover transformações, mesmo que precisando de provações, pois não se baseia apenas na produção, mas, sobretudo, na transformação pessoal que ele promove.

Muitas vezes, sentido e significado em relação ao trabalho podem atuar como sinônimos, no entanto, podem ser percebidos de maneira diversa. Codo (1997) define significado como algo que vai além da relação sujeito-objeto. Para o autor, há um circuito sujeito-trabalho-significado, e quanto mais completo e complexo for esse circuito, maior o prazer em executar o trabalho, sendo que sua ruptura pode ser fonte de sofrimento e, inclusive, trazer prejuízos à saúde. Dessa forma, o significado contempla a relação afetiva, não apenas concreta do indivíduo com seu trabalho.

Harper (2001) define sentido, tomado como a percepção, sentimento em relação ao trabalho, denotando algo mais relacionado ao indivíduo face à atividade que realiza, portanto, sem transcender a relação sujeito-objeto, sendo algo mais concreto, objetivo.

No caso dos pacientes com câncer, como argumenta Peteet (2000), podem ser observados significados diversos para o trabalho, sobretudo em relação à própria autoestima. Isso acontece principalmente quando veem suas funções laborais, ou mesmo outras, do próprio cotidiano, ameaçadas pelo aparecimento da doença. O diagnóstico de câncer e de outras doenças crônicas graves, como apropriadamente alerta Debert (2010), pode provocar rupturas bruscas, mudando o curso da vida do indivíduo.

Reforçam a concepção de significado do trabalho algumas falas dos participantes pesquisados, os quais, mesmo enfrentando uma doença grave, atribuem posicionamentos positivos quando questionados sobre o que o trabalho representa em suas vidas. Diante do diagnóstico de câncer, o trabalho e a possibilidade de executá-lo podem trazer saudades para quem não pode ou não consegue manter sua atividade, muitas vezes, significando a falta de algo fundamental em suas vidas. Além disso, a autoestima, o desafio e a satisfação proporcionados pelo trabalho podem motivar as pessoas na superação da doença e à realização de seu tratamento.

O trabalho para mim significa tudo, vida! Se sentir útil e realizada [...] a satisfação dos meus clientes que gostam muito dos meus produtos [...] [E6, 61 anos, confeiteira]

Significa tudo, dignidade, valorização [...] eu adoro trabalhar, se tiver condições físicas, volto ao trabalho [...] fico feliz em ver o resultado daquilo que estou aplicando para os alunos $[\ldots][\mathrm{E} 8,51$ anos, professora $]$

O trabalho dignifica e faz com que os dias tenham sentido [...] me sinto bem e útil desempenhando minha função. Considero importante o resultado obtido na formação do futuro dos cidadãos, fazer a diferença na vida dos pequenos, até porque acredito que viemos com uma missão, um propósito, e se pode dar sentido a tudo isso através do trabalho, realizando-se como pessoa e profissional, pois é uma atividade desafiadora, um constante aprendizado [...] [E13, 50 anos, professora]

É bom trabalhar, é bom você se sentir útil, viva [...] aprende a gostar [...] eu pelo menos, com tudo que eu trabalhei na vida inteira, eu aprendi a gostar, fazer com gosto. 
Realmente, trabalhar não são flores todos os dias, mas vale a pena. [E18, 51 anos, comerciante]

A relação entre trabalho e utilidade, além do aspecto de sentir-se útil, tem presença marcante na percepção dos sujeitos pesquisados. Fica explícito nas falas não apenas o trabalho com o sentido concreto (necessidade de sobrevivência, ganho pecuniário) na vida dos indivíduos, mas também sua relação não palpável, a do sentimento em relação ao trabalho, reforçando o conceito de significado do trabalho atribuído por Codo (1997).

Peteet (2000) menciona a melhora na autoestima obtida na relação com o trabalho para a pessoa com câncer. Além disso, conforme Dejours (1992), o trabalho pode ser um importante meio na constituição da identidade. As percepções dos sujeitos da pesquisa evidenciam a forte associação entre trabalho e identidade, além da representação do trabalho com a utilidade, trabalhar para se sentir sujeito, trabalhar para se sentir vivo. Ainda é possível perceber a concepção de integralidade do indivíduo pelo trabalho, quando se refere que "trabalho é tudo", remetendo à perspectiva de que a vida é definida pelo trabalho. Em oposição, a situação de não trabalho remete aos sentimentos de aflição, angústia, medo, inutilidade e desconforto aos indivíduos, um desengajamento doloroso, como mencionado por Peteet (2000) e Grunfeld e Cooper (2015) e expresso nas falas seguintes.

Não trabalhar me deixa aflito. [E5, 55 anos, produtor rural]

Quando a gente não pode trabalhar, daí a gente dá o valor [...] eu tinha medo de me sentir inútil, eu pensava: e aí, como é que vai ser? O que eu vou fazer? Fazia sete anos que aquilo ali era a minha vida [...] e aí, não vou fazer nada? Vou ficar uma inútil? [E18, 51 anos, comerciante]

Gill (2006) explica que pessoas com câncer para as quais a autoestima depende muito de suas carreiras profissionais podem expressar depressão pelo fato de não conseguirem trabalhar, o que fica evidenciado nas falas acima pela menção à aflição, ao medo e à inutilidade.

A pessoa diagnosticada com câncer, nesse contexto, não vivencia apenas o impacto de lidar com uma situação angustiante e debilitante física e psicologicamente que o diagnóstico e o tratamento envolvem. Ao se deparar com a redução ou a interrupção de suas atividades laborais para o tratamento da doença, ela enfrenta mudanças em sua trajetória pré-programada da vida. Diante disso, podem sobrevir dificuldades em diversos aspectos, tanto na manutenção e provisão de renda quanto em relação à angústia por sentir-se menos produtiva ou ao sofrimento gerado pelo desengajamento forçado de um trabalho com o qual o indivíduo se identificava fortemente (PETEET, 2000; GILL, 2006; GRUNFELD; COOPER, 2015). São muitas as questões relacionadas à identificação com a atividade laboral e à necessidade do trabalho no processo de recuperação da saúde. Para alguns, há necessidade de parar de trabalhar quando do diagnóstico de neoplasia maligna, e isso pode ser fonte de estranhamentos para os indivíduos.

A identificação com o trabalho é importante componente do papel social, sendo determinante nas relações interpessoais nas mais diversas esferas. $\mathrm{Na}$ família, por exemplo, o controle financeiro ajuda a definir o papel de provisão na renda, estabelecendo uma dinâmica familiar que costuma ser quebrada ante o adoecimento por câncer. Tudo isso pode trazer significativa ansiedade e até depressão para a pessoa cuja identidade está muito ligada a seu papel como provedor (PETEET, 2000).

O trabalho influencia a identidade, seja pela realização pessoal, seja pela forma de garantir subsistência, regular as organizações humanas, como um "mal necessário" ou como 
fonte de satisfação. Segundo Soares, Luna e Lima (2010), o trabalho ocupa a maior parte da vida, sendo um dos edificadores da identidade, além de ser algo fundamental nos diversos ciclos de vida do sujeito. Ter o que fazer representa, para os entrevistados, ser, constituir-se como sujeito ativo e útil, e, portanto, realizado, independentemente de ser remunerado financeiramente e/ ou da satisfação do cliente, além de permitir o contato social no espaço do trabalho, como é possível observar nas falas que seguem.

Eu me sentia feliz, Deus o livre, minha Nossa Senhora [...] amanhecer e a gente ajudar na criação, tirar leite, era muito bom [...] ter seu próprio dinheiro, sustento, ter amigos. [E3, 48 anos, serviços gerais]

Eu me sentia bem trabalhando, gostava, saía de casa, via outras pessoas, convivia... Se estivesse em casa já estava louca, depois que acostumei a sair de casa para trabalhar, era muito difícil ficar em casa novamente. [E10, 58 anos, gerente de padaria]

Não conseguia me imaginar sem meu trabalho, pois sempre me trouxe independência pessoal, financeira, liberdade para fazer as coisas [...] eu me sentia realizada, valorizada. [E11, 47 anos, secretária]

O trabalho para mim significa realização pessoal, gosto das atividades que realizo nesta empresa [...] meus colegas e a direção da empresa sempre estiveram me apoiando e incentivando [...] Através do meu trabalho, consigo manter minha família e realizar meus objetivos de vida e meus sonhos [...] [E14, 56 anos, gerente de compras]

Além de fonte de renda para a família, hoje considero minha terapia: terapia do trabalho. [E16, 52 anos, técnica em contabilidade]

Trabalho é pelo dinheiro e pelo fato de eu tá com pessoas toda hora. Eu não gosto de ficar sozinha, sempre gosto de tá com pessoas. [E20, 28 anos, balconista]

Para Peteet (2000), trabalhar pode ser uma maneira de o indivíduo com câncer se sentir independentizado, tanto física quanto emocional ou financeiramente. Para ele, permanecer ativo é uma forma de negar a mortalidade, escapar da ansiedade causada pela vulnerabilidade que advém do diagnóstico e do tratamento da doença. Assim, muitas pessoas com câncer optam por seguir trabalhando, sobretudo durante os processos terapêuticos, visando a manter-se ativos, com as ideias de integralidade, normalidade, liberdade, independência.

\subsection{Controle e normalidade da vida por meio do trabalho}

Se trabalhar traz o sentimento de estar vivo, ativo, não poder trabalhar implica em uma conotação de inatividade, inutilidade e, inclusive, de morte. Isso fica patente quando do adoecimento por câncer, que, além de ser uma doença altamente estigmatizante do ponto de vista social, traz com seu diagnóstico as diversas vulnerabilidades humanas, sejam estas abstratas, como o medo da morte, sejam estas reais, como o fato de não poder trabalhar, associado a suas consequências (PETEET, 2000; TAMMINGA et al., 2012; BARNARD; CLUR; JOUBERT, 2016).

O diagnóstico de câncer acarreta dificuldades para os indivíduos não somente no que tange à identidade, mas, sobretudo, na sensação de perda do controle, da normalidade e da integridade. Perder 
o controle sobre o próprio destino, incluindo o da vida profissional, é motivo de angústia para muitos (GILL, 2006; RAQUE-BOGDAN et al., 2015). A possibilidade de dependência de outras pessoas é também uma situação ansiogênica na medida em que, se a pessoa não puder trabalhar, tem a percepção de perda de sentido da vida, sentindo-se dependente em qualquer aspecto: financeiro, físico ou afetivo.

Para Peteet (2000), com o diagnóstico de câncer, pode haver a perda do controle não apenas do trabalho, mas também das emoções, do status prévio, do papel social e familiar. Sendo assim, trabalhar pode ser uma maneira de manter algum controle sobre a vida, já que a situação que se impõe está fora da possibilidade de escolha do indivíduo. Conforme esse autor, por meio do trabalho pode-se negar ou reduzir a ansiedade frente à possibilidade da morte. Trabalhar significaria normalidade, ou seja, seguir o curso predeterminado para a vida, mas estaria na dependência de saúde adequada para empreender as atividades, o que é interrompido na vida da pessoa doente de câncer. Como bem ilustra a fala de uma entrevistada, denotando a perda da capacidade de controle da vida:

É que adoecer não tá na mão da gente [...] [E18, 51 anos, comerciante]

De acordo com Clot (2007), o homem procura compatibilizar o mundo do trabalho com seus outros mundos, podendo as contradições serem superadas, moldando-se à própria exigência de unidade e integralidade do homem. Essa compatibilidade é desejada ainda que se trate de um ideal, impossível de ser alcançado. Debert (2010) postula que o trabalho do homem não ocorre isolado de outros aspectos de sua existência, sendo que uma esfera vital influi em outra. Assim, uma mudança no curso da vida, como o fato de adoecer de câncer, pode desencadear conflitos, fragilidade emocional e estranhamentos, um período de evidente instabilidade, conforme explicitado pelas falas dos entrevistados a seguir:

Até quando consigo um trabalho bom... Finalmente, veio o diagnóstico de câncer [...] me deu uma chacoalhada. [E1, 40 anos, zeladora]

Quando adoeci, minha vida mudou radicalmente [...] eu não conseguia trabalhar, não tinha condições, quis voltar antes [...] tentei, mas não consegui. [E2, 28 anos, operador de caixa]

Não consegui mais trabalhá depois que veio o câncer, tava dependendo dos otro... Imagine... Tinha que vivê com oitenta reais por mês... Isso depois de muita luta, que consegui um bolsa-família... Passei a dependê dos irmão e dos amigo. [E3, 48 anos, serviços gerais]

Fiquei louca [...] tive que deixar o trabalho de uma hora para outra para cuidar da minha vida, da minha saúde. Foi a primeira vez que tive que escolher entre o trabalho e o cuidado com a saúde. [E8, 51 anos, professora]

Quando fiz o exame de colonoscopia, jamais me passou pela cabeça um diagnóstico assim (pausa) ... Quando veio o resultado do carcinoma, de início foi difícil de acreditar, a partir daquele momento a minha vida parou. Tive que deixar filhos, casa, trabalho e ir em busca de tratamento. É um sentimento de impotência, de entrega, vontade de fugir da situação... Mas como não dá para fugir, enfrentei com muita força e fé. [E10, 34 anos, dentista] 
E agora, o que vai ser? [...] fiquei triste e preocupada [...] não posso mais trabalhar. [E10, 58 anos, gerente de padaria]

Parei de trabalhar a dois anos devido à cirurgia na coluna. Sinto muita falta do trabalho, fico frustrada e triste [...] acho deprimente ficar em casa. [E11, 47 anos, secretária]

Me senti impotente por não poder mais trabalhar como mecânico por causa da fraqueza e das dores. Tudo mudou, passei a sair menos [...] [E15, 49 anos, mecânico]

Eu não tenho medo de nada [...] eu acho que o pior mesmo já passei, do susto de tudo quando descobri [...] por que o cara sempre com uma saúde, uma vida assim ótima e tudo [...] e acontecer isso aí... [E19, 29 anos, vendedor]

As falas revelam sentimentos de frustração, dependência, instabilidade emocional, depressão, medo, surpresa, preocupação e impotência diante das mudanças inesperadas, que trazem dificuldades para diversos aspectos da vida diante da doença, sobretudo para o trabalho, destacando-se a perda do controle da vida. São exemplos do que afirma Clot (2007), quando trata da multiplicidade de mundos em que vive o indivíduo, além do trabalho. Nos depoimentos, sobressaem dificuldades percebidas, os aspectos negativos relacionados à incapacidade de trabalhar pela presença da doença, emergindo a consciência, por parte dos pacientes pesquisados, do quanto a saúde, a vida, costuma ser deixada em segundo plano: "deixar do trabalho para cuidar da saúde". De acordo com Gill (2006), a deprivação do trabalho traz ansiedade para quem não consegue mantê-lo, instala a insegurança, a vulnerabilidade física, a falta de força e de energia.

De outra parte, observamos que há indivíduos cuja resiliência pode fazer buscar no mundo do trabalho a força, o incentivo para superarem suas dificuldades, inclusive tentando restabelecer o controle e manter a sensação de normalidade, o que Clot (2007) denomina "sair de si". O trabalho, normalmente ressignificado, assume o papel de ocupar a mente, de oferecer um espaço de fuga, de distanciamento da doença, buscando o equilíbrio e a normalidade da vida.

Trabalho é bom para sair da rotina, sair de casa, para ter ocupação [...] no trabalho aconteceu isso ou aquilo [...] faz parte do cotidiano aquela correria. [E2, 28 anos, operador de caixa]

Senti que a doença não ia me impossibilitar de trabalhar e que seria normal continuar trabalhando. [E12, 55 anos, professora]

Após o descobrimento do câncer e o tempo de tratamento, sempre continuei trabalhando, me ausentando somente o tempo necessário para realizar as cirurgias e a recuperação. O tratamento de radioterapia e quimioterapia sempre fiz trabalhando. Preferia continuar trabalhando durante o tratamento de radioterapia e quimioterapia, mesmo às vezes me sentindo cansado, um pouco debilitado, pois o trabalho fazia com que tivesse ânimo para prosseguir o tratamento, que não é fácil [...] assim não me sentia doente [...] pois meus colegas e a direção da empresa sempre estiveram me apoiando e incentivando, bem como meus familiares, que estiveram sempre ao meu lado, não deixando que me abatesse totalmente devido à doença. [E14, 56 anos, gerente de compras] 
Continuo fazendo minhas atividades normais. Quando passam os efeitos da quimioterapia, os enjoos, mal-estar, vou para o trabalho, que considero minha melhor terapia. [E16, 52 anos, técnica em contabilidade]

Nesse contexto, o trabalho se reveste de sentimentos positivos. Dejours (2011) afirma que o trabalho obtém seus frutos da sua relação com a subjetividade e com o sujeito, contribuindo para dar sentido à vida, mas podendo proporcionar satisfações ou padecimentos. Pode provocar o pior, a doença e a morte, mas pode gerar o melhor, a saúde e o acréscimo de vida, podendo fazer os indivíduos se sentirem vivos e saudáveis ao trabalharem. O retorno à rotina do trabalho durante e após o tratamento possibilita o sentido de normalidade.

Por outro lado, para algumas pessoas, o trabalho, paradoxalmente, pode ter sido ou é atualmente fonte de padecimentos, levando a situações não desejadas, não controladas pelo indivíduo, anormais, reduzindo-lhe a qualidade de vida e contribuindo para o adoecimento. A necessidade de trabalhar e a ansiedade pelo não conseguir trabalhar pode "corroer a saúde psicológica do indivíduo da mesma forma que a silicose corrói os pulmões dos mineiros acometidos por silicose" (DEJOURS, 1993).

Trabalhá quando a gente pode é bom... Mas depois que fica doente é ruim [...] pensa que nesse serviço a gente ajuda muita gente [...] e a gente acaba se prejudicando... Mas não tem otra alternativa, mesmo sofrendo, tem que trabalhá. [E3, 48 anos, serviços gerais]

Considero o trabalho uma coisa boa, mas trabalhava por obrigação, por necessidade [...] [E7, 50 anos, do lar]

Esses últimos depoimentos fazem emergir percepções de que o trabalho implica, ao mesmo tempo, algo positivo para enfrentar os problemas da vida, mas também pode ser um agravante dos mesmos. Uma reflexão mais profunda dos participantes faz com que o cotidiano do trabalho seja ressignificado, com o entendimento de que ele nem sempre é ou era fonte de prazer, sendo executado por obrigação, motivo de sofrimento, mas necessário para a sobrevivência.

Dejours $(2007,2011)$, no entanto, defende que o trabalho tem o poder de transformar o sofrimento em prazer. Concordando nesse sentido, Mendes e Tamayo (2001) argumentam que essa conversão pode ocorrer quando há valorização e reconhecimento da importância do trabalhador. No âmbito deste estudo, a pessoa com câncer adquire essa valorização para si mesmo, para a família, para a organização onde está inserido e para a sociedade, buscando a superação da doença. Segundo esses autores, o trabalhador entra em uma esfera de aceitação, de admiração e de liberdade de expressão, como explicitam alguns dos entrevistados:

Hoje sou feliz trabalhando, já usei cadeira-de-rodas, precisei de oxigênio [...] me sentia muito fraco [...] sou feliz por poder trabalhar novamente depois da guerra que enfrentei $[\ldots]$ meus colegas de trabalho me ajudaram a vencer, me apoiaram. [E2, 28 anos, operador de caixa]

Adoro o meu trabalho, e no momento da descoberta do câncer, o mesmo foi fundamental em minha vida. Através do trabalho, me sentia amparada e acolhida pelos meus pacientes, que ao saber do problema que eu estava passando, foram prontos em me ajudar, com palavras de carinho, conforto, força, fé [...] foram feitas muitas orações [...] tudo isso me fortaleceu para que eu enfrentasse com mais força o meu problema. $\mathrm{O}$ trabalho também serviu para que o tempo passasse mais rápido, 
diminuindo a minha angústia. Não ter parado de trabalhar, deu, de certa forma, uma sensação de que tudo iria dar certo. $\mathrm{O}$ apoio dos meus pacientes e o convívio com eles neste período foi fundamental. [E9, 34 anos, dentista]

Por acreditar que o trabalho dignifica e tornaria meus dias com mais objetivo, optei por não me aposentar. [E14, 50 anos, professora]

Para Tamminga (2012), a pessoa doente de câncer pode ter, no desejo de retornar ao trabalho, um estímulo para vencer a doença e o tratamento. Voltar a trabalhar após uma doença como esta permite estabelecer uma pedra angular no curso da vida do indivíduo, que, muitas vezes, encontra um ambiente de trabalho onde há apoio dos pares e dos superiores, permitindo a inclusão e valorização do indivíduo, que teve muitas perdas com o adoecimento. Assim, há o restabelecimento da normalidade do indivíduo e, portanto, da normalidade por meio do trabalho. Há referência, também, nas falas anteriores, à superação experimentada pelo indivíduo na busca da retomada das responsabilidades, da normalidade e do controle, conforme já constatado por Amir, Neary e Luker (2008), Barnard, Clur e Joubert (2016), Tiedtke et al. (2014) e Tunceli et al. (2009) em publicações da psico-oncologia, que obtiveram resultados concordantes a esse respeito. Poder trabalhar em vigência de um câncer ou após a recuperação deste pode trazer ao indivíduo a percepção de haver algum controle sobre a própria vida ou a de recobrar a sensação de normalidade, usurpada pelo adoecimento (TUNCELI et al., 2009; TIEDTKE et al., 2014; MOFFATT; NOBLE, 2015).

As estratégias de enfrentamento, controle da doença, persistência, resiliência e esperança traçam planos realísticos de retornar ao trabalho, podendo ser fonte importante para a recuperação da normalidade do indivíduo (RAQUE-BOGDAN, 2015). Na concepção de Moffatt e Noble (2015), o trabalho pode, portanto, ser uma forma de reparar os danos causados pela doença e, nas falas dos sujeitos participantes do estudo, essa possibilidade está presente.

\section{CONSIDERAÇÕES FINAIS}

Este estudo objetivou compreender os processos de subjetivação do trabalho para a pessoa com câncer, sua identificação com o trabalho, bem como as percepções de controle e normalidade da vida que podem ser obtidas por meio do trabalho diante do adoecimento por câncer.

Em relação ao significado do trabalho para o paciente oncológico, ficaram evidentes atributos como autorrealização, ter uma ocupação, sentimento de utilidade, meio de sobrevivência, forma de organizar a rotina, sair de casa, melhorar a autoestima, dignidade, valorização, desafio, autonomia, liberdade, objetivo de vida, independência e, até mesmo, uma fuga diante da angústia de se deparar com uma doença como o câncer. Deve-se levar em conta, também, que muitas pessoas colocaram o trabalho como edificante da própria identidade, demonstrando angústia pelo fato de não conseguirem trabalhar face à doença e às limitações que advêm dela. Pode-se observar que, como decorrência do câncer, houve, para alguns, o sentimento de perda, seja pela incapacidade de ser o provedor da família, seja pelo desengajamento forçado, seja pela limitação do próprio convívio social, situações estas que trouxeram conflitos e desajustamento aos indivíduos.

Também foi possível perceber que trabalhar pode ser entendido como uma forma de manter o controle sobre algum aspecto da vida, já que não se pode ter controle sobre a doença e seu tratamento. Além do mais, o trabalho pode restabelecer, para o indivíduo, o senso 
de normalidade. Dessa forma, pessoas com maior escolarização apresentaram, neste estudo, maior desejo de seguirem trabalhando, sem afastar-se durante o tratamento, o que pode ser uma maneira de abstração e de não se sentirem tão fragilizados, doentes.

Torna-se claro, diante das falas dos participantes deste estudo, o valor conferido ao trabalho nas questões relativas à própria identidade, ao bem-estar, à autoestima, além do papel em relação à independência nos âmbitos financeiro, emocional, familiar e social, que conferem sentido e significado ao trabalho e à própria vida. Há deslocamento de sentido e significado do trabalho para os entrevistados deste estudo, sendo que aparece, com muita frequência, a ideia de estar vivo ao trabalhar, algo que não é tão evidente nas pessoas que não estão doentes de câncer. Além disso, a angústia pela impossibilidade do trabalho traz a conotação de medo do futuro, instabilidade emocional e dependência, que é muito forte em algumas falas, ligando o não trabalho a aspectos negativos.

Receber um diagnóstico de câncer muda o curso da vida do indivíduo, bem como sua percepção em relação a diversos aspectos, podendo haver ressignificação e inversão de prioridades em direção ao trabalho. Pelo trabalho e pela esperança de retornar à atividade, há a manutenção do desejo de viver, de superar as dificuldades trazidas pela doença e pelas terapias empregadas para seu combate. Todo esse tema trabalhado merece investigações adicionais futuras, uma vez que há limitação de exploração em apenas um estudo, pela amplitude e potencialidades de discussão do assunto.

\section{REFERÊNCIAS}

AMIR, Z.; NEARY, D.; LUKER, K. Cancer survivors' views of work 3 years post diagnosis: A UK perspective. European Journal of Oncology Nursing, v. 12, p. 190-197, 2008.

ANTUNES, R. Os sentidos do trabalho: ensaio sobre a afirmação e a negação do trabalho. São Paulo: Boitempo Editorial, 1999.

ANTUNES, R. Século XXI: A nova era da precarização estrutural do trabalho? In: DAL ROSSO, S.; FORTES, J. A. A. S. Condições de trabalho no limiar do século XXI. Brasília: Época, 2008. p. 13-19.

BARDIN, L. Análise de conteúdo. Lisboa: Edições 70, 2000.

BARNARD. A.; CLUR, L.; JOUBERT. Y. Returning to work: the cancer survivor's transformational journey of adjustment and coping. International Journal of Qualitative Studies on Health and Well-being, v. 11, p. 32488, 2016.

BORGES, L. O.; TAMAYO, A. A estrutura cognitiva do significado do trabalho. Revista Psicologia: Organizações e Trabalho, Brasília, v. 1, n. 2, p. 11-44, jul./dez. 2001.

BRASIL. Instituto Nacional do Câncer (INCA). Estimativas 2016 para o Câncer no Brasil. Rio de Janeiro, 2016. Disponível em: http://www.inca.gov.br/estimativa/2016/. Acesso em: 5 maio 2021.

CARVALHO, C. S. U. Anecessária atenção à família do paciente oncológico. Revista Brasileira de Cancerologia, Rio de Janeiro, v. 54, n. 1, p. 97-102, 2008.

CLOT, Y. A função psicológica do trabalho. 2. ed. Petrópolis: Vozes, 2007.

CODO, W. Um diagnóstico integrado do trabalho com ênfase em saúde mental. In: JACQUES, M. G.; CODO, W. (Orgs.) Saúde mental \& trabalho: leituras. 3. ed. Petrópolis: Vozes, 1997. p. $173-90$. 
CODO, W.; SAMPAIO, J. J. C.; HITOMI, A. H. Indivíduo, trabalho e sofrimento: uma abordagem interdisciplinar. 3. ed. Petrópolis: Vozes, 1998.

DEBERT, G. G. A dissolução da vida adulta e a juventude como valor. Horizontes Antropológicos, Porto Alegre, v. 16, n. 34, jul./dez. 2010.

DEJOURS, C. A banalização da injustiça social. 6. ed. Rio de Janeiro: Editora da FGV, 2005.

DEJOURS, C. A loucura do trabalho: estudo de psicopatologia do trabalho. 5. ed. amp., São Paulo: Cortez Oboré, 1992.

. Psicodinâmica do trabalho na pós-modernidade. In: MENDES, A. M; LIMA, S. C. C.; FACAS, E. P. (Orgs.). Diálogos em psicodinâmica do trabalho. Brasília: Paralelo 15, 2007. p. 13-26. 2004.

Subjetividade, trabalho e ação. Revista Produção, São Paulo, v. 14, n. 3, p. 27-34, Trabalhar não é derrogar. Laboreal, Porto, v. 7, n. 1, p. 76-80, jul. 2011.

O trabalho como enigma. In: LANCMAN, S.; SZNELWAR, L. I. (Orgs.). Cristophe Dejours: da psicopatologia à psicodinâmica do trabalho. 2. ed. Rio de Janeiro/Brasília: Fiocruz/ Paralelo 15, 2008. p. 123-141.

Travail: usure mentale. 10. ed. Paris: Bayard Éditions, 1993.

DENZIN, N. K.; LINCOLN, Y. S. O planejamento da pesquisa qualitativa: teorias e abordagens. Porto Alegre: Bookman, 2011.

DUNCAN, B. B. et al. Doenças crônicas não transmissíveis no Brasil: prioridade para enfrentamento e investigação. Revista de Saúde Pública, São Paulo, v. 46, n. 1, p. 126-34, 2012.

ENRIQUEZ, E. Perda do trabalho, perda da identidade. In: NABUCO, M. R.; CARVALHO NETO, A. (Orgs.) Relações de trabalho contemporâneas. Belo Horizonte: IRT da PUCMG. 1999. p. 69-83.

FALQUETO, J.; FARIAS, J. Saturação teórica em pesquisas qualitativas: relato de uma experiência de aplicação em estudo na área de administração. Investigação Qualitativa em Ciências Sociais. v. 3, n. 1, p. 560-8, 2016.

FLICK, U. A pesquisa qualitativa: relevância, história, aspectos. In: FLICK, U. Uma introdução à pesquisa qualitativa. Porto Alegre: Bookman, 2009.

FONTANELLA, B. J. B.; RICAS, J; TURATO, E. R. Amostragem por saturação em pesquisas qualitativas em saúde: contribuições teóricas. Cadernos de Saúde Pública, Rio de Janeiro, v. 24, n. 1, p. 17-27, 2008.

FREUD, S. O mal-estar na civilização: novas conferências à psicanálise e outros textos. São Paulo: Companhia das Letras, 2010. v. 18. (Coleção Obras Completas).

GILL, F. The meaning of work: lessons from sociology, psychology, and political theory. Journal of Socio-Economics, v. 28, p.725-743, 2006.

GRUNFELD, E.; COOPER, A. Employment transitions among câncer survivors: a longitudinal qualitative exploration of the meaning and performance of work. Psycho-Oncology, v. 24, suppl. 2, p. 1-103, 2015. 
HARPER, D. Online Etymology Dictionary, 2001. Disponível em: http://www.dictionary. com/browse/harper. Acesso: 5 maio 2021.

HARVEY, D. Condição pós-moderna: uma pesquisa sobre as origens da mudança cultural. 9. ed. São Paulo: Loyola, 2000.

HEWITT, M.; GREENFIELD, S.; STOVALL E. (Ed.). From cancer patient to cancer survivor: lost in transition. Washington: National Academies Press, 2006.

KORNBLITH, A. Psychosocial adaptation of cancer survivors. In: HOLLAND, J. C. (Org.). Psycho-oncology. New York: Oxford, 1998.

LANCMAN, S. O mundo do trabalho e a psicodinâmica do trabalho. In: LANCMAN, S.; SZNELWAR, L. I. (Orgs.). Christophe Dejours: da psicopatologia à psicodinâmica do trabalho. 2. ed. Rio de Janeiro/Brasília: Fiocruz/Paralelo 15, 2008.

LONGO, C. J. et al. No examination of cancer patients' monthly out-of-pochet costs in Ontario, Canada. European Journal of Cancer Care, v. 16, n. 6, p. 500-507, 2007.

MARQUES, C. A proteção ao trabalho penoso. São Paulo: LTr, 2007.

MENDES, A. M.; TAMAYO, A. Valores Organizacionais e prazer sofrimento no trabalho. Psico USF, Itatiba, v. 6, n. 1, p. 39-46, jun. 2001.

MÉSZÁROS, I. Philosophy, Ideology \& Social Science. Sussex: Wheastsheaf Books, 1986. MINAYO, M. C. S. Pesquisa social: teoria, método e criatividade. 34. ed. Petrópolis: Vozes, 2013.

MINAYO, M. C. S.; SANCHES, O. Quantitativo-qualitativo: oposição ou complementaridade? Cadernos de Saúde Pública, Rio de Janeiro, v. 9, n. 3, p. 239-262, jul./set. 1993.

MOFFATT, S.; NOBLE, E. Work or welfare after cancer? Explorations of identity and stigma. Sociology of Health and Illness. v. 37, n. 8, p. 1191-1205, 2015.

MORIN, E. M. La quête du sens au travail. Le papier a présenté dedans 9e Congrès International de l'Associantion de Psychologie du travail de langue française. Sherbrooke, Canadá, 1996.

. Os sentidos do trabalho. Revista de Administração de Empresas, São Paulo, v. 41, n. 3, p. 8-19, jul./set. 2001.

MORIN, E. M.; TONELLI, M. J.; PLIOPAS, A. L. V. O trabalho e seus sentidos. Psicologia \& Sociedade, Porto Alegre, v. 19, n. especial, p. 38-46, jun. 2007.

PETEET, J. R. Cancer and the Meaning of Work. General Hospital Psychiatry, v. 22, p. 200205, 2000.

RAQUE-BOGDAN, T. L. et al. The work life and career development of young breast cancer survivors. Journal of Counseling Psychology, v. 62, n. 4, p. 655-669, 2015.

SANDELOWSKY, M. Sample size in qualitative research. Research in Nursing \& Health, v. 18, n. 2, p. 179-183, 1995.

SIEGEL, R. L.; MILLER, K. D.; JEMAL, A. Cancer Statistics, 2017. Cancer Journal for Clinicians, v. 67, n. 1, p. 7-30, 2017.

SOARES, D. H. P; LUNA, I. N; LIMA, M. B. de F. A arte de aposentar-se: programa de preparação para aposentadoria com policiais federais. Estudos Interdisciplinares do Envelhecimento, Porto Alegre, v. 15, n. 2, p. 293-313, 2010. 
TAMMINGA, S. J. et al. Breast cancer survivors' views of factors that influence the return-towork process - a qualitative study. Scandinavian Journal of Work, Environment \& Health, v. 38, n. 2, p. 144-154, 2012.

TIEDTKE, C. et al. Return to work following breast cancer treatment: the employers' side. Journal of Occupational Rehabilitation, v. 24, p. 399-409, 2014.

TOLFO, S. R.; PICCININI, V. Sentidos e significados do trabalho: explorando conceitos, variáveis e estudos empíricos brasileiros. Revista Psicologia \& Sociedade, Porto Alegre, v. 19, edição especial, p. 38-46, maio 2007.

TUNCELI, K. et al. Cancer survivorship, health insurance, and employment transitions among older workers. National Institutes of Health Public Access. v. 46, n. 1, p. 17-32, 2009.

WORLD HEALTH ORGANIZATION. Health in 2015: from MDGs, millennium development goals to SDGs, sustainable development goals. Geneva: World Health Organization, 2015. Disponível em http://apps.who.int/iris/bitstream/10665/200009/1/9789241565110_eng.pdf. Acesso em: 5 maio 2021. 